\title{
Update on Sports Participation for Athletes with Implantable Cardioverter Defibrillators
}

Rachel Lampert

Yale School of Medicine, New Haven, Connecticut - USA

\section{Abstract}

Prior statements have recommended restriction from competitive sports participation for all athletes with ICDs. Recent data, however, suggests that many athletes can participate in sports without adverse events. In the ICD Sports Registry, 440 athletes, aged 8-60 years, 77 of which were high-level interscholastic athletes, who had continued to practice sports, were prospectively followed for 4 years, with no deaths or failures to defibrillate during practice, and no injuries related to arrhythmia or shock during sports. Shocks did occur, for ventricular and supraventricular arrhythmias. While more athletes received shocks during physical activity than at rest, there were no differences between competition or practice, versus other physical activity. Programming with higher rate cut-offs and longer durations was associated with fewer inappropriate shocks, with no increase in syncope. Based on this study, current recommendations now state that returning to competition may be considered for an athlete with an ICD. In considering this decision, the underlying disease and type of sport should be discussed, and shared decision-making between doctor, patient, and often family, is critical.

\section{Introduction}

The number of athletes diagnosed with cardiovascular disease placing them at risk for sudden death, whether through presentation with symptoms such as syncope or cardiac arrest, or through screening efforts, will likely continue to increase. In Europe, ECG screening of athletes is recommended by professional societies ${ }^{1}$ and while consensus statements in the US continue to support pre-participation evaluation (PPE) with just history and physical examination, ${ }^{2}$ these too may diagnose lifethreatening cardiac conditions, and many universities in the US have added ECG to the PPE. ${ }^{3}$ Furthermore, family cascade screening increases the rate of diagnosis of asymptomatic family members after presentation of a symptomatic proband. ${ }^{4,5}$ Many of these symptomatic and asymptomatic athletes will receive defibrillators, raising the question of the safety of returning to practice.

\section{Historical perspective}

Until recently, consensus statements from the American College of Cardiology and European Society for Cardiology $y^{6-8}$ advised that patients with ICDs should not participate in sports more vigorous than the "IA" class, low-dynamic/low-static activities such as bowling or golf. The basis for these recommendations were postulated risks, based on the consensus of experts, of failure to defibrillate, injury caused by loss of control due to arrhythmia-related syncope and/or shock, or damage to the ICD system. However, restriction from sports also has downsides, as the psychological as well as physiological benefits of exercise and sports are well-

\section{Keywords}

Athlete; Implantable Cardioverter Defibrillator.

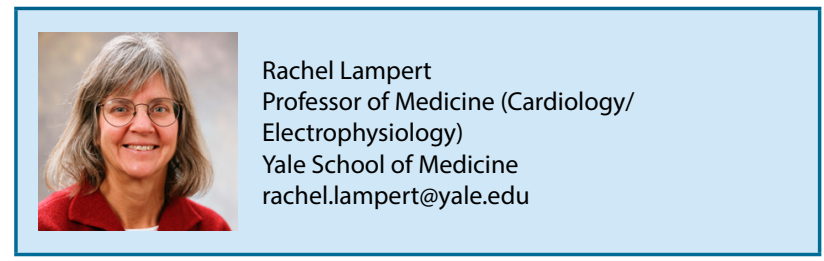

Mailing Address: Rachel Lampert

Yale School of Medicine - 789 Howard Avenue. Postal Code: 06520-8055, New Haven, Connecticut - USA

E-mail: rachel.lampert@yale.edu 
known. Restriction from sports, for any reason, has been shown to decrease both physical and emotional quality of life for athletes. ${ }^{9}$ For many adolescents with ICDs, restriction from sports was the biggest factor impacting their quality of life. ${ }^{10}$

Further, a 2006 retrospective survey of Heart Rhythm Society physician-members, ${ }^{11}$ suggested that many ICD patients were participating in sports, despite the consensus recommendations, and and the survey respondents did not describe adverse events. While survey results are limited by selection and recall bias, these results suggested that a prospective registry of athletes with ICDs was feasible, ethical, and necessary. Feasible, as many ICD patients were participating in sports. Ethical, as study participants were already practicing sports and were not asked to perform activities of which safety was unknown. Necessary, as if the risks were as high as hypothesized, those participating needed to know, while if the risks were not so high, others might choose to participate. Based on the preliminary results provided by this survey, the ICD Sports Safety Registry, a multinational, prospective, observational registry, was established to identify and quantify risks associated with sports participation for ICD patients.

\section{The ICD sports registry}

In this study, of which two-year results were published in 2013 and four-year results in 2017, ${ }^{12,13} 440$ athletes with ICDs, aged 10-60 years, 2/3 males, $46 \%$ with a history of ventricular arrhythmia (secondary prevention) who had chosen to continue competing in sports higher than Class "IA" regarding static/dynamic intensity, were prospectively followed. Participants were contacted regularly during the follow-up, and ICD records obtained, and rhythms adjudicated for shocks received at any time. The most common cardiac diagnoses were LQTS, HCM, and CAD, and the most common sports, running, soccer, and basketball. Among the twenty athletes participating at the university interscholastic level, diagnoses were similar, and the sports included soccer, basketball, lacrosse, and others. ${ }^{14}$

Over a median follow-up of 44 months, there were no occurrences of the primary endpoints-no failures of the ICD to defibrillate or externally resuscitated arrests, and no injuries due to syncopal arrhythmia or loss of control following shock. The 95\% confidence interval for the occurrence of adverse events based on 376 participants followed for at least 2 years was $0 \%$ to $0.9 \%$ and based on 167 participants followed for at least 4 years, it was $0 \%$ to $2.2 \%$. Many participants received shocks, with forty-six (10\%) receiving appropriate shocks (for VT/ $\mathrm{VF}$ ) during competition or practice, a rate of 3 per 100 person-years. While more athletes received shocks during some form of physical activity than during rest, there was no difference between competition/practice and other physical activities. ${ }^{13}$ In this population, older athletes were more likely to receive shocks during sports than those under 18 years old.

While the ICD Registry demonstrated that it is safe for many athletes with ICDs to continue competing, whether ventricular arrhythmias requiring shock for termination are more common in competitive athletes is yet to be determined. A subanalysis of the ICD Registry which compared the primary population with a subpopulation of intensive recreational athletes enrolled in Europe ${ }^{15}$ (and not described in the papers focused on competitive athletes) suggested that arrhythmias with physical activity were more common in those competing. However, there were differences between the European and US athletes. In the general population, the "paradox of exercise" is well-described. ${ }^{16}$ While overall, sudden death is less common in those who exercise vigorously, the risk of an event is higher during exercise. While often considered a "paradox", this is likely explained by the role of the autonomic nervous system in arrhythmogenesis. Catecholamines are known to promote arrhythmias. ${ }^{17}$ For well-conditioned individuals, catecholamines will be at the highest levels when they are vigorously exercising. Whether a similar "paradox of exercise" exists in the most common genetic cardiovascular diseases in the athlete-ICD population, is unknown. An ongoing observational study, the "Exercise in Genetic Cardiovascular Disease" (NIH \# R01 HL125918-01) is currently enrolling individuals with HCM and LQTS (in two parallel studies, Lifestyle and Exercise in HCM (LIVE-HCM) and Lifestyle and Exercise in LQTS (LIVELQTS) at all levels of exercise, both with and without ICDs, to determine whether arrhythmic endpoints are more or less frequent in patients who exercise when compared to those who do not (http:/ / www.livehcm. org/ and http://livelqts.org/).

The impact of shocks on quality of life was not measured in the ICD Sports Registry. ICD shocks decrease quality of life, as shown in many studies. ${ }^{18}$ However, while about one-third of those athletes who received shocks during sports stopped playing one or 
all sports for a period of time, most returned to sports later on, suggesting that the beneficial impacts of sports participation on quality of life outweighed the negative impact of shocks for most athletes.

\section{Programming the ICD in the athlete}

A recent subanalysis ${ }^{19}$ has focused on the appropriate programming to minimize the likelihood of inappropriate shocks in this population. In the ICD Sports Study, those athletes whose ICDs were programmed with higher rate-cut-offs for the first therapy zone (greater than $200 \mathrm{bpm}$ ), and those programmed with detectionduration greater than the nominal settings, were less likely to receive inappropriate shocks, and those with both these settings, the least likely. ${ }^{19}$ Programming was not prescribed in this study, but findings were similar to large randomized controlled studies in the general ICD population. ${ }^{20}$ There was no increase in syncope prior to shock in those athletes with higher rate-cut-off/longer duration. While two athletes had ventricular tachycardia below the rate cut-off and thus not treated, the arrhythmias were minimally symptomatic, presenting as palpitations. There was no difference in shock-rates based on dual-versus-single chamber device, or number of therapy zones.

Based on data from the ICD Sports Registry, in the updated "Eligibility and Disqualification Recommendations for Competitive Athletes With Cardiovascular Abnormalities: Task Force 9: Arrhythmias and Conduction Defects: A Scientific Statement From the American Heart Association and American College of Cardiology", ${ }^{21}$ competitive sports participation for patients with an ICD no longer carries a blanket restriction, but rather, a "IIB" recommendation, i.e., "may be considered".

Factors in the decision-making process around return to play: importance of the underlying disease

What factors need to be considered in the decisionmaking process around return to play for an athlete with an ICD? The most important one is the underlying disease. The ICD Sports Registry has not evaluated if or to what degree vigorous exercise may exacerbate the progression of cardiomyopathies. While in that study the ICD was always successful at converting ventricular arrhythmias in patients with arrhythmogenic right ventricular cardiomyopathy (ARVC,) these were the patients most likely to experience both single and storms of ventricular arrhythmias during sports. Furthermore, there are increasing data in both animals $^{22,23}$ and human patients ${ }^{24,25}$ that high-level exercise may accelerate cardiomyopathy progression in this disorder. For patients with ARVC, the disease process, rather than the ICD itself, should guide the risk-evaluation of sports participation.

How exercise may impact the myopathic process in HCM is yet to be clarified. In a murine model of HCM, exercise was actually beneficial. In animals who had not yet developed the HCM phenotype, exercise prevented fibrosis and myocyte disarray, and in animals who had already developed HCM, exercise led to disarray regression and to improvements in the apoptotic signaling pathway components. ${ }^{26}$ In a recent study of controlled increases in moderate exercise in sedentary HCM patients, ${ }^{27}$ physical conditioning improved, there were no arrhythmias, and no changes in echo parameters, although this was a short intervention, and did not include maximal vigorous exercise.

Catecholaminergic polymorphic VT (CPVT) is unique in that an ICD is not nearly as successful at converting an arrhythmia as it is in other arrhythmogenic conditions. ${ }^{28}$ ICD shocks increase catecholamines, even in a sedated patient ${ }^{17}$ and this can create a vicious cycle of arrhythmia recurrence for a patient with CPVT. One small series has described appropriately-treated CPVT patients, mostly without ICDs, participating in sports. ${ }^{29}$ In one series of 15 CPVT patients with ICDs, 6 were treated for ventricular arrhythmias. Two died of VT refractory to ICD treatment, including one whose VT was triggered by an inappropriate shock for $\mathrm{AF}^{28}$ In the ICD Sports Registry, another subset of patients with ventricular arrhythmias requiring multiple shocks for termination were those with "idiopathic VF". As CPVT is electrically silent at rest, it is highly possible that some "idiopathic VF" may represent undiagnosed CPVT. Treadmill testing is imperative to evaluate CPVT, and genetic testing should be considered.

\section{Factors in decision-making: sports}

The type of sports should also be taken into consideration. In the ICD Sports Registry, there were few athletes engaged in high-level contact sports. Basketball and soccer, which are considered "contact sports" by the American Academy of Pediatrics, ${ }^{30}$ comprised a significant proportion of the sports practiced by the athletes, but there were very few engaged in sports in 
which violent contact was an intrinsic and purposeful part of the practice, such as American football or hockey. In the ICD Sports Registry, lead malfunction rates were similar to those reported in unselected populations, ${ }^{31}$ but whether the risk of damage to the ICD system is higher during the practice of the more violent contact sports remains undetermined.

\section{Importance of shared decision-making}

Finally, the most important consideration is the athlete's values and preferences, and often his or her family's, and a shared decision-making approach is imperative. ${ }^{32}$ Shared decision-making, termed the "pinnacle of patient-centered care",33 requires the physician to explain the risks and benefits of options and to help patients understand how to reconcile these options with their personal preferences and values. This means full discussion with the patients, and often with their families--What are the risks? What data do we have, and how does this patient compare to the patients in the studies? For instance, for a hockey player, it is important to explain that system damage may be greater. What data are lacking? For instance, as mentioned above, while we know that shocks occur during sports, whether shocks would be less likely with the discontinuation of sports is still unknown. Furthermore, while there has been no adverse events described in the 440 patients in the ICD Sports Registry over four years, this study is not large enough to declare that the risk is zero. What do the professional society guidelines recommend? What does this patient and family think about risk in general? For instance, some families allow their children to climb Mount Everest, while others would not allow them to play American football. This shared decision-making approach requires a combination of knowledge of the data, and willingness to engage the patients (and often their families) as partners in the decision-making process. Most importantly, we need to stress that we do not have all the answers, while providing a framework for decision-making.

\section{Author contributions}

Acquisition of data: Lampert R. Analysis and interpretation of the data: Lampert R. Obtaining financing: Lampert R. Writing of the manuscript: Lampert R. Critical revision of the manuscript for intellectual content: Lampert R.

\section{Potential Conflict of Interest}

There is potential conflict of interest in relation to research grants from Medtronic, Boston Scientific, and Abbott/St Jude which supported much of the work described in the review. Honoraria/advisory board Medtronic.

\section{Sources of Funding}

This study was funded by Medtronic, Boston Scientific and St. Jude Abbot.

\section{Study Association}

This study is not associated with any thesis or dissertation work.

\section{Ethics approval and consent to participate}

This study was approved by the Ethics Committee of the Yale Human Investigation Committee under the protocol number 0608001736. All the procedures in this study were in accordance with the 1975 Helsinki Declaration, updated in 2013. Informed consent was obtained from all participants included in the study.

\section{References}

1. Mont L, Pelliccia A, Sharma S, Biffi A, Borjesson M, Terradellas JB, et al. Pre-participation cardiovascular evaluation for athletic participants to prevent sudden death: Position paper from the EHRA and the EACPR, branches of the ESC. Endorsed by APHRS, HRS, and SOLAECE. Europace. 2017;19(1):139-63.

2. Maron BJ, Friedman RA, Kligfield P, Levine BD, Viskin S, Chaitman BR, et al. Assessment of the 12-lead ECG as a screening test for detection of cardiovascular disease in healthy general populations of young people (12-25 Years of Age): a scientific statement from the American Heart

Association and the American College of Cardiology. Circulation. 2014;130(15):1303-34.

3. Coris EE, Sahebzamani F, Curtis A, Jennings J, Walz SM, Nugent D, et al. Preparticipation cardiovascular screening among National Collegiate Athletic Association Division I institutions. Br J Sports Med. 2013;47(3):182-4.

4. Ackerman MJ, Priori SG, Willems S, Berul C, Brugada R, Calkins H, et al. HRS/EHRA expert consensus statement on the state of genetic 
testing for the channelopathies and cardiomyopathies this document was developed as a partnership between the Heart Rhythm Society (HRS) and the European Heart Rhythm Association (EHRA). Heart Rhythm. 2011;8(8):1308-39.

5. Priori SG, Wilde AA, Horie M, Cho Y, Behr ER, Berul C, et al. HRS/ EHRA/APHRS expert consensus statement on the diagnosis and management of patients with inherited primary arrhythmia syndromes: document endorsed by HRS, EHRA, and APHRS in May 2013 and by ACCF, AHA, PACES, and AEPC in June 2013. Heart Rhythm. 2013;10(12):1932-63.

6. Maron BJ, Zipes DP. 36th Bethesda Conference: Eligibility recommendations for competitive athletes with cardiovascular abnormalities. J Am Coll Cardiol. 2005;45(8):1313-75.

7. Pelliccia A, Fagard R, Bjørnstad HH, Anastassakis A, Arbustini E, Assanelli D, et al. Recommendations for competitive sports participation in athletes with cardiovascular disease: a consensus document from the Study Group of Sports Cardiology of the Working Group of Cardiac Rehabilitation and Exercise Physiology and the Working Group of Myocardial and Pericardial Diseases of the European Society of Cardiology. Eur Heart J. 2005;26(14):1422-45.

8. Heidbuchel H, Corrado D, Biffi A, Hoffmann E, Panhuyzen-Goedkoop $\mathrm{N}$, Hoogsteen J, et al. Recommendations for participation in leisure-time physical activity and competitive sports of patients with arrhythmias and potentially arrhythmogenic conditions. Part II: ventricular arrhythmias, channelopathies and implantable defibrillators. Eur J Cardiovasc Prev Rehabil. 2006;13(5):676-86.

9. McAllister DR, Motamedi AR, Hame SL, Shapiro MS, Dorey FJ. Quality of life assessment in elite collegiate athletes. Am J Sports Med. 2001;29(6):806-10.

10. Rahman B, Macciocca I, Sahhar M, Kamberi S, Connell V, Duncan RE. Adolescents with implantable cardioverter defibrillators: a patient and parent perspective. Pacing Clin Electrophysiol. 2012;35(1):62-72.

11. Lampert R, Cannom D, Olshansky B. Safety of sports participation in patients with implantable cardioverter-defibrillators: A survey of Heart Rhythm Society Members. J Cardiovasc Electrophysiol. 2006;17(1):11-5.

12. Lampert R, Olshansky B, Heidbuchel H, Lawless C, Saarel E, Ackerman $\mathrm{M}$, et al. Safety of sports for athletes with implantable cardioverterdefibrillators: results of a prospective, multinational registry. Circulation. 2013;127(20):2021-30.

13. Lampert R, Olshansky B, Heidbuchel H, Lawless C, Saarel E, Ackerman $\mathrm{M}$, et al. Safety of sports for athletes with implantable cardioverterdefibrillators: long-term results of a prospective multinational registry. Circulation. 2017;135(23):2310-2.

14. Saarel EV, Law I, Berul CI, Ackerman MJ, Kanter RJ, Sanatani S, et al. Safety of sports for young patients with implantable cardioverterdefibrillators. Circ Arrhythm Electrophysiol. 2018;11(11):e006305.

15. Heidbuchel H, Willems R, Jordaens L, Olshansky B, Carre F, Lozano IF, et al. Intensive recreational athletes in the prospective multinational ICD Sports Safety Registry: Results from the European cohort. Eur J Prev Cardiol. 2019;26(7):764-75.

16. Maron BJ. The paradox of exercise. N Engl J Med. 2000;343(19):1409-11.

17. Lampert R, Soufer R, McPherson CA, Batsford WP, Tirado S, Earley $\mathrm{C}$, et al. Implantable cardioverter-defibrillator shocks increase T-wave alternans. J Cardiovasc Electrophysiol. 2007;18(5):512-7.

18. Schron EB, Exner DV, Yao Q, Jenkins LS, Steinberg JS, Cook JR, et al. Quality of life in the antiarrhythmics versus implantable defibrillators. Circulation. 2002;105(5):589-594.
19. Olshansky B, Atteya G, Cannom D, HeidbuchelH, Saarel EV, Anfinsen OG, et al. Competitive athletes with implantable cardioverter defibrillators: How to program? Data from the Implantable CardioverterDefibrillator Sports Registry. Heart Rhythm. 2019;16(4):581-7

20. Moss AJ, Schuger C, Beck CA, Brown MW, Cannom DS, Daubert JP, et al. Reduction in Inappropriate Therapy and Mortality through ICD Programming. N Eng J Med. 2012;367(24):2275-83.

21. Zipes DP, Link MS, Ackerman MJ, Kovacs RJ, Myerburg RJ, Estes NA. Eligibility and disqualification recommendations for competitive athletes with cardiovascular abnormalities: task force 9: arrhythmias and conduction defects: a scientific statement from the American Heart Association and American College of Cardiology. Circulation. 2015;132(22):e315-25.

22. Kirchhof P, Fabritz L, Zwiener M, Witt H, Schäfers M, Zellerhoff S, et al. Age- and training-dependent development of arrhythmogenic right ventricular cardiomyopathy in heterozygous plakoglobin-deficient mice. Circulation .2006;114:1799-806.

23. Cruz FM, Sanz-Rosa D, Roche-Molina M, García-Prieto J, García-Ruiz JM, Pizarro G, et al. Exercise Triggers ARVC Phenotype in Mice Expressing a Disease-Causing Mutated Version of Human Plakophilin-2. J Am Coll Cardiol. 2015;65(14):1438-50.

24. James CA, Bhonsale A, Tichnell C, Murra yB, Russell SD, Tandri H, et al. Exercise increases age-related penetrance and arrhythmic risk in arrhythmogenic right ventricular dysplasia/cardiomyopathyassociated desmosomal mutation carriers. J Am Coll Cardiol. 2013;62(14):1290-7.

25. Rojas A, Calkins H. Present understandingoftherelationship between exercise andarrhythmogenicrightventricular dysplasia / cardiomyopathy. Trends Cardiovasc Med. 2015;25(3):181-8.

26. Konhilas JP, Watson PA, Maass A, Boucek DM, Horn T, Stauffer BL, et al. Exercise can prevent and reverse the severity of hypertrophic cardiomyopathy. Circ Res. 2006;98(4):540-8.

27. Saberi S, Wheeler M, Bragg-Gresham J, Hornsby W, Agarwal PP, Attili A, et al. Effect of moderate-intensity exercise training on peak oxygen consumption in patients with hypertrophic cardiomyopathy: a randomized clinical trial. JAMA. 2017;317(13):1349-57.

28. Sy RW, Gollob MH, Klein GJ, Yee R, Skanes AC, Gula LJ, et al. Arrhythmia characterization and long-term outcomes in catecholaminergic polymorphic ventricular tachycardia. Heart Rhythm. 2011;8(6):864-71.

29. Ostby SA, Bos JM, Owen HJ, Wackel PL, Cannon B, Ackerman MJ Competitive Sports Participation in Patients With Catecholaminergic Polymorphic Ventricular Tachycardia. JACC Clin Electrophysiol. 2016;2(3):253-62.

30. Rice SG; American Academy of Pediatrics Council on Sports Medicine and Fitness. Medical conditions affecting sports participation. Pediatrics. 2008;121(4):841-8.

31. Kramer DB, Maisel WH. Guidelines for managing pacemaker and implantable defibrillator advisories. In: Ellenbogen KA, ed. Clinical cardiac pacing, defibrillation, and resynchronization therapy. Philadelphia: Elsevier Saunders; 2011.

32. Baggish AL, Ackerman MJ, Lampert R. Competitive Sport Participation Among Athletes With Heart Disease: A Call for a Paradigm Shift in Decision Making. Circulation. 2017;136(17):1569-71.

33. Barry MJ, Edgman-Levitan S. Shared decision making — The pinnacle of patient-centered care. N Engl J Med. 2012;366(9):780-781. 